\title{
Composition of ready-to-eat-cereals and their eligibility for marketing to children. How much does Cyprus deviate from the WHO Nutrient Profile Model?
}

\section{Authors:}

Arsenios Tselengidis ${ }^{\mathrm{a}}$, Victoria Virginia Beeks ${ }^{\mathrm{a}}$, Georgia Hadjimichael ${ }^{\mathrm{a}}$ and Stella Antoniou ${ }^{\mathrm{a}}$

Affiliation:

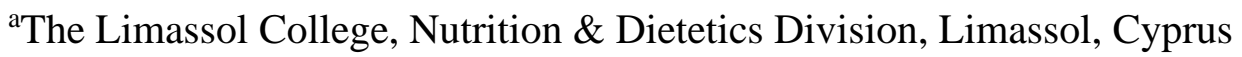

Correspondence to Dr. Stella Antoniou (stella_antoniou_1@hotmail.com)

Acknowledgements:

We thank Dr Iona Fitzpatrick for her assistance with the text editing and for her comments that greatly improved the manuscript.

\section{Declaration:}

The authors do not have any conflicts of interest and did not receive any funding for the development of this manuscript. 


\section{ABSTRACT}

Background: Governments have introduced legislative activities, such as restricting marketing to children of foods high in fat, sugar and/or salt, to curb the childhood obesity burden. In the European Region, the World Health Organization (WHO/Europe) has facilitated them with the development of the Nutrient Profile Model (WHO/Europe-NPM). Cyprus is the country with the highest childhood obesity rates in the Region. Nonetheless, it does not currently restrict marketing to children. The purpose of this study is to evaluate the composition of ready-to-eat-cereals (RTECs), a fat, sugar and/or salt dense food product category on the Cypriot market and to examine whether the marketing of these products to children should be permitted according to the WHO/Europe-NPM.

Methods: Two hundred RTEC samples from four national food retailers were collected from March to April 2018. The samples were assessed for their nutritional quality with the use of the WHO/Europe-NPM and statistical comparisons were performed between child-targeted and non-child-targeted RTECs.

Results: The average content of sugar and salt was significantly higher in "child-targeted" than in "non-child-targeted" RTECs. 87.3\% of the "child-targeted" RTECs would not be permitted for marketing to children according to the WHO/Europe-NPM and $73.5 \%$ of the overall sample exceeded at least one of the WHO/Europe-NPM recommendations for fat, sugar and/or salt.

Conclusions: In case of the implementation of any marketing restriction legislation domestically in the future, most of the RTECs currently sold in Cyprus would not be permitted to be marketed to children according to the WHO/Europe-NPM. Incorporating marketing restrictions in the health policy agenda and adopting the WHO/Europe-NPM may improve the childhood obesity rates in Cyprus.

Keywords: breakfast cereal, nutrient composition 


\section{INTRODUCTION}

Childhood obesity is one of the most serious public health challenges of the $21^{\text {st }}$ century (WHO 2018d), and has increased with alarming rates in the last decades, now affecting more than 158 million children worldwide (Lobstein and Brinsden 2019). The World Obesity Federation predicts 48 million more children will be obese by 2025 and this may reach 254 million by 2030 (Lobstein and Brinsden 2019). In the countries of the European Region, overweight and obesity rates range from 9 to 43 percent and 5 to 43 percent for boys and girls respectively between 6 and 9 years old (WHO 2018a). Cyprus is the leader amongst these countries, with $43 \%$ of its children classified as obese or overweight (WHO 2018a).

Dietary patterns are important determinants of childhood obesity. Large prospective studies support the association between breakfast consumption and lower risk of obesity and weight gain (Purslow et al. 2008; Heijden et al. 2007). Studies suggest that eating a healthy breakfast is related to a greater intake of nutrients throughout the day, better coverage of the nutritional recommendations, better quality of the whole diet (López-Sobaler et al. 2018), as well as an improvement in cognitive performance (Adolphus et al. 2016) and social interaction (Adolphus et al. 2013). A systematic review from Mullan and Singh (2010), summarises the results from 24 studies, the majority of them conducted with children and/or adolescents, and identifies ready-to-eat cereals (RTECs) as amongst the most commonly consumed breakfast items. RTECs are an important source of macro- and micro-nutrients, but they can also be energy dense foods, high in fat, sugar and/or salt (HFSS).

WHO has highlighted the negative impact of high levels of fat, sugar and salt on health and has published relevant intake recommendations for these ingredients (WHO 2018c, 2015a, 2012). It also recommends the reduction of marketing for HFSS foods to children as part of broader efforts to tackle increasing levels of childhood obesity (WHO 2010). The marketing of unhealthy products has been identified as one of the main factors that negatively contribute to children's food preferences and dietary patterns (Giménez et al. 2017). In 2015, the WHORegional Office for Europe, after taking under consideration several European Nutrient Profile Models, developed the "WHO Regional Office for Europe Nutrient Profile Model" (WHO/Europe-NPM)(WHO 2015b).

The WHO/Europe-NPM is recognised by the WHO as a critical tool that facilitates governments aiming to introduce regulatory strategies related to the prevention of obesity (WHO 2015b) such as restrictions of marketing of unhealthy foods to children, introduction of warning labels, and implementation of fiscal policies aiming the reduction of HFSS food consumption (WHO 2013). This tool classifies food products based on their "nutritional composition for reasons related to preventing disease and promoting health" (WHO 2013). Specifically, depending on the nutritional content of the foods (on total fat, saturated fat, total sugars, added sugars and salt) marketing to children can be "permitted" or not (WHO 2015b). This model is stricter than existing marketing self-regulatory industry models such as the EU Pledge (Storcksdieck et al. 2015). Thus several European member states have adopted it or reformulated their existing models according to it (WHO 2018b). The WHO/Europe-NPM includes 17 food categories. Category 6 refers exclusively to RTECs (WHO 2015b). Marketing of RTECs is not permitted if they contain total fat more than $10 \mathrm{~g} / 100 \mathrm{~g}$ of product, total sugars more than $15 \mathrm{~g} / 100 \mathrm{~g}$ of product or salt more than $1.6 \mathrm{~g} / 100 \mathrm{~g}$ of product (WHO 2015b).

Cyprus does not have a national Nutrient Profile Model nor a national Nutrition Action Plan for restricting the marketing of foods HFSS to children. Nevertheless, the Ministry of Health 
does have national nutrient intake recommendations (Ministry of Health 2008a, 2008b) which are in line with the WHO recommendations. No published studies have examined the extent to which RTECs have excessive levels of HFSS on the Cypriot market.

The purpose of this study is to evaluate the composition of RTECs, a fat, sugar and/or salt dense food product category on the Cypriot market and to examine whether the marketing of these products to children should be permitted according to the WHO/Europe-NPM.

\section{METHODS}

This cross-sectional study assesses the nutritional quality of RTECs (child-targeted and nonchild-targeted) in Cyprus and investigates whether their marketing would be permitted within the framework of the WHO/Europe-NPM. Statistical comparisons between child- and nonchild-targeted cereals were performed.

\section{Data Collection}

We identified four national food retail chains that were present in the four main cities of the country. In one of the cities, at the largest store from each of the four national retailers, one of the researchers took pictures of RTECs ( $n=288)$ with a smartphone, from March to April 2018. Five pictures for each RTEC were taken (front and back of the package, price, barcode, and nutritional labelling). Duplicated products or products with missing data or illegible pictures were excluded ( $\mathrm{n}=88$ ), leaving 200 individual RTECs for analysis. For each product, the following data were collected in a Microsoft ${ }^{\circledR}$ Excel 2013 data set: company name, product name, barcode, if product was child-targeted or not (see below), and the nutritional information (without milk added) from the nutritional information table on the product package. The information included: total fat, total sugars, and salt (g/100g $1 \mathrm{~g}$ of sodium is equivalent to about $2.5 \mathrm{~g}$ of salt) (WHO 2015b). According to the WHO/Europe-NPM criteria (WHO 2015b), the content of these nutrients is required for classifying whether marketing of each RTEC to children is to be permitted.

For the category of the RTECs, the WHO/Europe-NPM directive is that countries "may choose to include a threshold for minimum dietary fibre content, for example $>6 \mathrm{~g}$ dietary fibre" (WHO 2015b). This variable was not included in the analysis, as it might have overestimated the healthiness of the RTECs which were still high in at least one of the other three detrimental to health ingredients. When a nutrient is negligible in a product it can be labelled as 'trace'. Hence, where the salt content of a RTEC was displayed as 'trace' $(n=6)$, its reported value was given as $0.00 \mathrm{~g}$.

\section{Assessment of child-targeting}

We considered a RTEC to be "child-targeted" if the food package featured any of the following: candy; child-directed images; child-directed messages designed to attract attention; encouraged interaction with the product (e.g. games); mention of children in their brand name or logo; inclusion in tie-ins to children's TV shows, movies, or musical acts; or used primary colours and cartoon-like fonts in order to be appealing to children (Potvin Kent, Cameron, and Philippe 2017). Otherwise, the product was classified as "non-child-targeted". Two authors examined and classified each of the products' pictures. Inter-rater reliability test with Cohen's Kappa was performed (95\% agreement). 


\section{Nutrition Quality of RTECS}

The nutrition quality of the RTECs was assessed using the WHO/Europe-NPM (WHO 2015b). Unlike other national models, the WHO/Europe-NPM does not use a scoring system, where points are allocated based on the nutrient content of $100 \mathrm{~g}$ of a food or drink and assess the overall nutrition composition as "less healthy" or "healthy". Instead, it proposes marketing prohibition when a product exceeds any of the ingredient recommendations for each food category. Accordingly, the term "marketing not permitted" was assigned if a RTEC exceeded $10 \mathrm{~g}$ in total fat, $15 \mathrm{~g}$ in total sugars, or $1.6 \mathrm{~g}$ in salt per $100 \mathrm{~g}$ of product (WHO 2015b). Any RTECs with all three nutrient contents below the WHO recommendations was graded as "marketing permitted". At this point, the authors would like to bring to the reader's attention that the references to marketing permission throughout the text, refer to the WHO's recommendation and not to a currently existing Cypriot law.

\section{Statistical Analysis}

Data for each ingredient are reported as total number (n), percentage (\%), mean $(\bar{x})$, standard deviation (SD), median, and range of the minimum-maximum values (Min, Max). As suggested by the WHO/Europe-NPM (WHO 2015b), the nutrient values were standardised per $100 \mathrm{~g}$ of product. In all tests carried out, significance was deemed at $\mathrm{p}<0.05$. All analysis was conducted using the statistical package IBM SPSS Statistics version 24.0.

Comparison between child-targeted and non-child-targeted cereals: Independent-samples t-test was used to compare the levels of fat, sugars and salt between the child-targeted and nonchild-targeted cereals.

Evaluation of marketing permission between child-targeted and non-child-targeted cereals: The child-targeted and non-child-targeted cereals were stratified according to whether they exceeded any of the upper limits set by the WHO/Europe-NPM or not ("marketing not permitted" and "marketing permitted" groups respectively). Then, the chi squared $\left(\chi^{2}\right)$ test was conducted to investigate possible differences between the child-targeted and non-child-targeted cereals based on the marketing permission criteria, and whether there was an association between marketing permission and child-targeting.

\section{RESULTS}

This study examined 200 RTECs, where 55 (27.5\%) products were deemed to be "childtargeted" and the rest 145 (72.5\%) were deemed to be "non-child-targeted". The overall average nutritional composition per $100 \mathrm{~g}$ of these products was: $6.57 \mathrm{~g}$ (SD: 6.06) total fat, 18.05g (SD: 9.82) total sugars and 0.54g (SD: 0.62) salt. Classifying the cereals into "childtargeted" and "non-child-targeted" RTECs, the corresponding composition for the former was: 3.76g (SD: 3.77) total fat, 25.02g (SD: 8.99) total sugars and 0.67g. (SD: 0.49) salt, while for the later it was: 7.64g (SD: 6.43) total fat, 15.41g (SD: 8.80) total sugars and 0.49g (SD: 0.69) salt. The average content of total sugars and salt was significantly higher in the "child-targeted" RTECs than the "non-child-targeted" ones. In contrast, the fat content was significantly lower (as shown in Table 1). 
Table 1: Average nutrition composition per $100 \mathrm{~g}$ of child-targeted and non-child-targeted ready-to-eat cereals, sold on the Cypriot market, 2018

\begin{tabular}{lcccccc}
\hline & All cereals & $\begin{array}{c}\text { Child- } \\
\text { targeted } \\
(\mathrm{n}=55)\end{array}$ & $\begin{array}{c}\text { Non-child- } \\
\text { targeted } \\
(\mathrm{n}=145)\end{array}$ & t-test & p-values \\
\hline Total fat (g) & $\bar{x}$ (SD) & $6.57(6.06)$ & $3.76(3.77)$ & $7.64(6.43)$ & $-4.21(198)$ & 0.000 \\
& Median & 4.60 & 2.90 & 6.20 & & \\
& Min & 0.30 & 0.30 & 0.60 & & \\
Sugars (g) & Max & 29.6 & 17.00 & 29.60 & & \\
& $\bar{x}$ (SD) & $18.05(9.82)$ & $25.02(8.99)$ & $15.41(8.80)$ & $6.86(198)$ & 0.000 \\
& Median & 19.90 & 25.70 & 17.00 & & \\
Salt (g) & Min & 0.40 & 1.00 & 0.40 & & \\
& Max & 43.00 & 43.00 & 35.00 & & \\
& $\bar{x}$ (SD) & $0.54(0.62)$ & $0.67(0.49)$ & $0.49(0.69)$ & $1.90(198)$ & 0.014 \\
& Median & 0.47 & 0.65 & 0.28 & & \\
& Min & 0.00 & 0.03 & 0.00 & & \\
& Max & 6.20 & 1.80 & 6.20 & & \\
\hline
\end{tabular}

Abbreviations: $d f$, degrees of freedom; $S D$, standard deviation; $\bar{x}$, mean; min., minimum value; max., maximum value

When the data are stratified according to the WHO/Europe-NPM criteria, approximately three quarters ( $n=147 ; 73.5 \%)$ of the total RTECs and two thirds ( $=99 ; 68.3 \%)$ of the adult addressed RTECs exceeded in at least one criterion. Meanwhile, by examining the "childtargeted" RTECs alone, the percentage of the RTECs not permitted for marketing climbs up to $87.3 \%(\mathrm{n}=48)$. There was a significant association between marketing and child-targeting $\left(\chi^{2}\right.$ $=7.38(d f=1), p=.001$ ) (as shown in Table 2).

Table 2: Number and percentage of the child-targeted and non-child-targeted ready-to-eat cereals sold in the Cypriot market in 2018, stratified according to the WHO/Europe's Nutrient Profile Model

\begin{tabular}{lccccc}
\hline & All cereals & $\begin{array}{c}\text { Child- } \\
\text { targeted } \\
\mathrm{n}(\%)\end{array}$ & $\begin{array}{c}\text { Non-child- } \\
\text { targeted } \\
\mathrm{n}(\%)\end{array}$ & $\begin{array}{c}\chi^{2} \\
(\mathrm{df})\end{array}$ & p-value \\
\hline Marketing permitted & $53(26.5)$ & $7(12.7)$ & $46(31.7)$ & $7.38(1)$ & 0.001 \\
Marketing not permitted & $147(73.5)$ & $48(87.3)$ & $99(68.3)$ & & \\
Total & $200(100)$ & $55(100)$ & $145(100)$ & & \\
\hline
\end{tabular}

Abbreviations: $d f$, degrees of freedom

\section{DISCUSSION}

The current study examined the nutritional content of RTECs sold in the Cypriot market between March and April 2018. According to the WHO/Europe-NPM's criteria, three quarters of the reviewed RTECs would be subject to marketing restriction as they exceed the WHO recommendations on fat, sugar and/or salt. Applying the same criteria to child-targeting RTECs, then only around 10\% would be permitted to be advertised. This suggests that Cypriot 
children have limited access to healthy RTEC alternatives with levels of fat, sugar and salt within WHO recommended limits.

Among the ingredients, fat was the only ingredient whose presence was lower in child-targeted RTECs than in non-child-targeted RTECs. However, that was the main ingredient of the nonchild-targeted cereals that exceeded the recommendations by the WHO/Europe-NPM. These findings might be explained by the presence of nuts and seeds which increase the total amount of fat. Meanwhile, sugar and salt were the ingredients that were significantly higher in childtargeted breakfast cereals when compared to non-child-targeted cereals. These high sugar levels in breakfast cereals targeted towards children is worrisome since increased consumption of sugars is associated with weight gain and dental caries (WHO 2015a).

Our study's findings are in agreement with the findings of other studies investigating the sugar composition of breakfast cereals. Germer et al. (2013) in Germany found 28.2g/100g (versus our $25.02 \mathrm{~g} / 100 \mathrm{~g}$ ) average sugar content in RTECs advertised to children and $18.1 \mathrm{~g} / 100 \mathrm{~g}$ (versus our $15.41 \mathrm{~g} / 100 \mathrm{~g}$ ) in the non-child targeted RTECs. Similarly, in the United Kingdom in 2015, Pombo-Rodrigues et al. (2017) reported 20.83g of sugar per $100 \mathrm{~g}$ of product in the overall RTECs examined versus the $26.90 \mathrm{~g} / 100 \mathrm{~g}$ on RTECs addressed to children. Rito et al. (2019) applied the same criteria of the WHO/Europe-NPM in Portugal and observed that 84,6\% (versus our $87.3 \%$ ) of RTECs were non-compliant regarding the sugar content. Pestano and his colleagues (2011) showed that most breakfast cereals are not healthy enough to be advertised to children, particularly because of their high sugar content.

There is no doubt that the food industry and food advertising affect children's nutritional eating behaviours. The food industry must do more to ensure that consumers, and especially children, have access to healthier consumables.

In addition, as for Government of Cyprus, actions needed should include focus on the development of a national nutrient profile model in accordance to the WHO/Europe-NPM's classification criteria. Based upon this model, several legislative activities can be considered, such as; comprehensive marketing regulation of foods HFSS targeting children in the media, including digital advertising, regulation of school food environments (foods sold in schools and foods advertised around school yards), development of warning labels for food products exceeding the WHO suggested upper limits, recommendations for food reformulation, introduction of fiscal policies (e.g. taxation of sugar sweetened beverages) and identifying and subsidising food products that could improve children's diet (e.g. fruits and vegetables). The plan should also take into consideration and align with the two targets mentioned, but no further details have been reported, in the national "Strategy on the Rights of the Child in Health: 20172025” (Ministry of Health 2017). Namely a) the re-activation of the National Committee about Nutrition for updating the nutritional guidelines which have not been updated since first published in 2008 (Ministry of Health 2008a, 2008b), and b) the inter-ministerial (Ministries of Education, Culture and Health) collaboration for the development, implementation and enforcement of a food marketing legislation.

\section{LIMITATIONS}

There are a few methodological limitations to be acknowledged. We did not manage to identify a list of all food retailers in Cyprus. Since Cyprus is an island country with a relatively small geographical size, we assumed that the four biggest retailers would provide an adequate and representative sample of the RTEC market during the study period. As such, we may have failed to include RTECs provided by small neighbourhood stores or imported RTECs that are 
sold at stores exclusively targeting the most common ethnic minorities living in the country (e.g. Russian, Chinese). Additionally, during data collection, we noticed that retailers would add new products to the RTECs shelves quite often. This could suggest that the RTECs examined might be seasonal and the results of our study might represent only the specific data collection period. Future studies which consider longer timeframes and sample additional retailers would be beneficial.

This study is limited to data taken from the nutritional composition table on the product packages and is based on the assumption that these labels are an accurate representation of the nutritional content. We did not investigate the origin of the "sugars" named on the label: whether they were added sugars (e.g. chocolate, biscuits) or whether they originated from honey, syrups or juices of fruits and vegetables. Future studies should fill in these gaps and stratify the Cypriot RTECs according to cereal types (e.g. cornflakes, cookie crisps, chocolate cereals, puffed wheat) (Rito et al. 2019).

\section{CONCLUSION}

Ready-to-eat-cereals could be an integral part of a healthy meal and make a significant contribution to health. They can be high in fibre, rich in iron, vitamins and various trace elements. However, 87.3\% of RTECs existing in the Cypriot market exceed the WHO recommendations for unhealthy ingredients and should not be marketed to children, largely due to their high sugar content. Local governments wishing to improve public health should implement stricter regulations and set out clear strategies for adopting the WHO/Europe-NPM. 


\section{REFERENCES}

Adolphus, Katie, Clare L. Lawton, and Louise Dye. 2013. "The Effects of Breakfast on Behavior and Academic Performance in Children and Adolescents." Frontiers in Human Neuroscience 7 (August): 1-28. https://doi.org/10.3389/fnhum.2013.00425.

Adolphus, Katie, Clare L Lawton, Claire L Champ, and Louise Dye. 2016. "The Effects of Breakfast and Breakfast Composition on Cognition in Children and Adolescents: A Systematic Review.” Advances in Nutrition 7 (3): 590S-612S. https://doi.org/10.3945/an.115.010256.

Germer, Stephanie, Carolin Hilzendegen, and Nanette Stroebele-Benschop. 2013. "Sugar Content of German Cereals for Children Recommendations and Reality.” Ernahrungs Umschau 60 (6): 89-95. https://doi.org/10.4455/eu2013.018.

Giménez, Ana, Luis de Saldamando, María Rosa Curutchet, and Gastón Ares. 2017. "Package Design and Nutritional Profile of Foods Targeted at Children in Supermarkets in Montevideo, Uruguay.” Cadernos de Saúde Pública 33 (5): 1-11. https://doi.org/10.1590/0102-311x00032116.

Heijden, Amber, Frank B Hu, Eric B Rimm, and Rob van Dam. 2007. "Diet and Physical Activity A Prospective Study of Breakfast Consumption and Weight Gain among U . S . Men.” Obesity 15 (10): 2463-69. https://doi.org/10.1016/j.cclet.2014.11.028.

Lobstein, Tim, and Hannah Brinsden. 2019. “Atlas of Childhood Obesity.” London, United Kingdom. http://s3-eu-west-1.amazonaws.com/woffiles/11996_Childhood_Obesity_Atlas_Report_ART_V2.pdf.

López-Sobaler, Ana M., Esther Cuadrado-Soto, África Peral Suárez, Aránzazu Aparicio, and Rosa M. Ortega. 2018. “Importancia Del Desayuno En La Mejora Nutricional y Sanitaria de La Población.” Nutrición Hospitalaria 35 (6): 0-1. https://doi.org/10.20960/nh.2278.

Ministry of Health. 2008a. "[National Recommendation of Nutrition and Physical Activity]

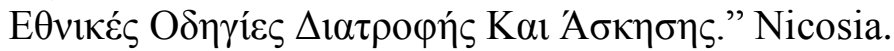
https://www.moh.gov.cy/Moh/MOH.nsf/All/ADDB0B13026ADB5AC2257A4C001DC

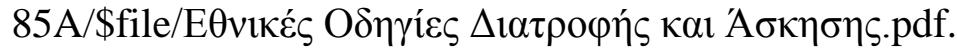

- 2008b. "[National Recommendations for Nutrition and Physical Activity for

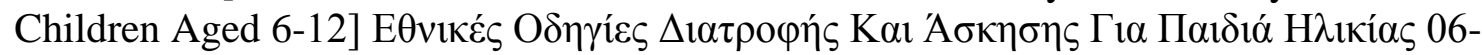
12 Xpovóv.” Nicosia. https://www.moh.gov.cy/Moh/MOH.nsf/All/ADDB0B13026ADB5AC2257A4C001DC

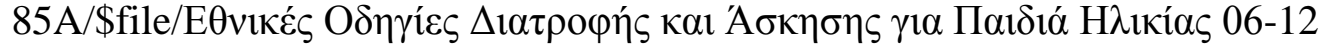
Xpovóv.pdf.

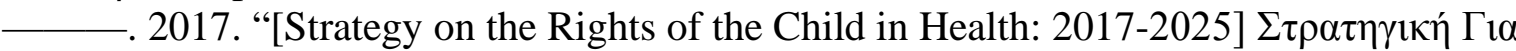

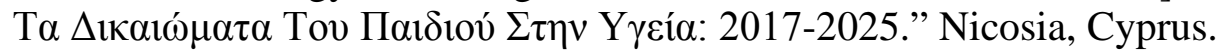
https://www.moh.gov.cy/Moh/MOH.nsf/All/CF11E3FEED896019C2258138001FF9E4/

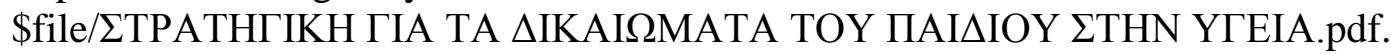

Mullan, Barbara Ann, and Monika Singh. 2010. "A Systematic Review of the Quality, Content, and Context of Breakfast Consumption.” Nutrition and Food Science 40 (1): 81-114. https://doi.org/10.1108/00346651011015953.

Pestano, Paul, Etan Yeshua, and Jane Joulihan. 2011. "Sugar in Children's Cereals: Popular Brands Pack More Sugar than Snack Cakes and Cookies.” Washington, DC. https://static.ewg.org/reports/2011/cereals/pdf/2011-EWG-Cereals-Report.pdf.

Pombo-Rodrigues, Sonia, Kawther M. Hashem, Feng J. He, and Graham A. Macgregor. 2017. "Salt and Sugars Content of Breakfast Cereals in the UK from 1992 to 2015." Public Health Nutrition 20 (8): 1500-1512. https://doi.org/10.1017/S1368980016003463. 
Potvin Kent, Monique, Cher Cameron, and Sarah Philippe. 2017. "The Healthfulness and Prominence of Sugar in Child-Targeted Breakfast Cereals in Canada.” Health Promotion and Chronic Disease Prevention in Canada. 2017. https://doi.org/10.24095/hpcdp.37.9.02.

Purslow, Lisa R., Manjinder S. Sandhu, Nita Forouhi, Elizabeth H. Young, Robert N. Luben, Ailsa A. Welch, Kay Tee Khaw, Sheila A. Bingham, and Nicholas J. Wareham. 2008. "Energy Intake at Breakfast and Weight Change: Prospective Study of 6,764 MiddleAged Men and Women.” American Journal of Epidemiology 167 (2): 188-92. https://doi.org/10.1093/aje/kwm309.

Rito, Ana Isabel, Ana Dinis, Carla Rascôa, António Maia, Inês de Carvalho Martins, Mariana Santos, João Lima, Sofia Mendes, Joana Padrão, and Camila Stein-Novais. 2019. "Improving Breakfast Patterns of Portuguese Children —an Evaluation of Ready-to-Eat Cereals According to the European Nutrient Profile Model.” European Journal of Clinical Nutrition 73 (3): 465-73. https://doi.org/10.1038/s41430-018-0235-6.

Savva, Savvas C., Yiannis A. Kourides, Charalampos Hadjigeorgiou, and Michael J. Tornaritis. 2014. "Overweight and Obesity Prevalence and Trends in Children and Adolescents in Cyprus 2000-2010.” Obesity Research \& Clinical Practice 8 (5): e42634. https://doi.org/10.1016/j.orcp.2013.11.005.

Storcksdieck, Stefan, Sandra Caldeira, Jan Wollgast, and Tsz Ning Mak. 2015. “Comparison of the Nutrient Profiling Schemes of the EU Pledge and the World Health Organization Regional Office for Europe.” https://doi.org/10.2787/24358.

Tornaritis, Michael J., Elena Philippou, Charalambos Hadjigeorgiou, Yiannis A. Kourides, Adamos Panayi, and Savvas C. Savva. 2014. "A Study of the Dietary Intake of Cypriot Children and Adolescents Aged 6-18 Years and the Association of Mother's Educational Status and Children's Weight Status on Adherence to Nutritional Recommendations.” BMC Public Health 14 (13): 1-11. https://doi.org/10.1186/1471-2458-14-13.

WHO. 2010. "Set of Recommendations on the Marketing of Foods and Non-Alcoholic Beverages to Children.” Geneva, Switzerland. http://apps.who.int/iris/bitstream/handle/10665/44416/9789241500210_eng.pdf;jsessioni $\mathrm{d}=5$ FC08CD498B6E6F51A65B131163FEEA4?sequence=1. . 2012. "Guideline: Sodium Intake for Adults and Children.” Geneva, Switzerland. https://www.who.int/nutrition/publications/guidelines/sodium_intake_printversion.pdf.

—. 2013. "Nutrient Profiling.” 2013. https://www.who.int/nutrition/topics/profiling/en/. . 2015a. "Guideline : Sugars Intake for Adults and Children." Geneva, Switzerland. https://doi.org/978 9241549028.

—. 2015b. "WHO Regional Office for Europe: Nutrient Profile Model.” Copenhagen, Denmark. https://doi.org/10.1021/cm0344764.

—. 2018a. "COSI Factsheet: Childhood Obesity Surveillance Initiative Highlights 201517.” Copenhagen, Denmark. https://doi.org/10.1111/j.2047-6310.2012.00068.x.

—. 2018b. "Evaluating Implementation of the WHO Set of Challenges and Guidance for next Steps in the WHO Non-Alcoholic Beverages to Children: Progress,

Recommendations on the Marketing of Foods and European Region.” Copenhagen, Denmark. http://www.euro.who.int/ data/assets/pdf file/0003/384015/food-marketingkids-eng.pdf?ua=1\%0ACopyright.

- 2018c. "Guidelines: Saturated Fatty Acid and Trans-Fatty Acid Intake for Adults and Children.” Geneva, Switzerland. - 2018d. "WHO European Childhood Obesity Surveillance Initiative: Overweight and Obesity among 6-9-Year-Old Children.” Copenhagen. http://www.euro.who.int/_data/assets/pdf_file/0010/378865/COSI-3.pdf?ua=1. 